\title{
Disruption of the Bcchs3a Chitin Synthase Gene in Botrytis cinerea Is Responsible for Altered Adhesion and Overstimulation of Host Plant Immunity
}

\author{
Delphine Arbelet, ${ }^{1,2,3}$ Pierrette Malfatti, ${ }^{1,2,3}$ Elizabeth Simond-Côte, ${ }^{1,2,3}$ Thierry Fontaine, ${ }^{4}$ Loïc Desquilbet, ${ }^{3}$ \\ Dominique Expert, ${ }^{1,2,3,5}$ Caroline Kunz, ${ }^{1,2,3}$ and Marie-Christine Soulié ${ }^{1,2,3}$ \\ ${ }^{1}$ UPMC Univ Paris 06, UMR217, F-75005, Paris, France; ${ }^{2}$ INRA, UMR217, F-75005, Paris, France; ${ }^{3}$ AgroParisTech, \\ UMR217, Laboratoire d'Interactions Plantes-Pathogènes, 16 rue Claude Bernard, 75231 Paris cedex 05, France; ${ }^{4}$ Unitié \\ des Aspergillus, Institut Pasteur, 25 rue du Docteur Roux, 75724 Paris cedex 15, France; ${ }^{5} \mathrm{CNRS}$, Laboratoire d'Interactions \\ Plantes-Pathogènes, 16 rue Claude Bernard, 75231 Paris cedex 05, France
}

Submitted 25 February 2010. Accepted 22 June 2010.

\begin{abstract}
The fungal cell wall is a dynamic structure that protects the cell from different environmental stresses suggesting that wall synthesizing enzymes are of great importance for fungal virulence. Previously, we reported the isolation and characterization of a mutant in class III chitin synthase, Bcchs $3 a$, in the phytopathogenic fungus Botrytis cinerea. We demonstrated that virulence of this mutant is severely impaired. Here, we describe the virulence phenotype of the cell-wall mutant Bcchs $3 a$ on the model plant Arabidopsis thaliana and analyze its virulence properties, using a variety of $A$. thaliana mutants. We found that mutant Bcchs $3 a$ is virulent on pad2 and pad3 mutant leaves defective in camalexin. Mutant Bcchs3a was not more susceptible towards camalexin than the wild-type strain but induced phytoalexin accumulation at the infection site on Col-0 plants. Moreover, this increase in camalexin was correlated with overexpression of the $P A D 3$ gene observed as early as $18 \mathrm{~h}$ postinoculation. The infection process of the mutant mycelium was always delayed by $48 \mathrm{~h}$, even on pad3 plants, probably because of lack of mycelium adhesion. No loss in virulence was found when Bcchs $3 a$ conidia were used as the inoculum source. Collectively, these data led us to assign a critical role to the BcCHS3a chitin synthase isoform, both in fungal virulence and plant defense response.
\end{abstract}

Botrytis cinerea Pers. FR (perfect stage: Botryotinia fuckeliana (de Bary) Whetzel) is the causal agent of gray mold diseases affecting a broad range of plant species, resulting in considerable economic losses. This necrotrophic pathogen has different modes of attack with diverse inocula sources, such as mycelia or conidia (Choquer et al. 2007). Until now, the control of Botrytis diseases relied on the frequent use of fungicides, leading to the development of resistant strains (Leroux et al. 2002). Effective control of this pathogen is dependent on the development of new strategies.

The fungal cell wall provides both protective and virulence functions towards the host (Latgé 2007). For example, this

C Kunz and M-C Soulié participated equally to this work.

Current address of L. Desquilbet: Unité des Maladies Contagieuses, Ecole Nationale Vétérinaire d'Alfort, 94704 Maisons-Alfort, France.

Corresponding author: M.-C. Soulié; Telephone: +33 1440886 08; Fax: +33144081631; E-mail: marie-christine.soulie@upmc.fr complex barrier protects the cell from changes in osmotic pressure imposed by the environment and, at the same time, must retain adequate plasticity to allow cell growth. In addition, the wall mediates the fungal cell adherence to the host and serves as a signaling center to activate signal transduction pathways within the host cell. Changes in cell-wall structure lead to severe defects in fungal morphology and consequently, impact fungal aggressiveness (Garcera-Teruel et al. 2004; Liu et al. 2004; Madrid et al. 2003; Munro et al. 2001; Sanz et al. 2005; Soulié et al. 2006). These vital roles of the fungal cell wall suggested it as a source for new targets of antifungal agents (Bowman and Free 2006; Latgé 2007).

Chitin, a long linear homopolymer of $\beta$-1,4-linked $N$-acetylglucosamine, is one of the essential components of the fungal wall. This molecule is biosynthesized by a family of membrane proteins, the chitin synthases (CHS). Blast analysis of all amino acid sequences of CHS allowed the identification of seven classes of fungal CHS in filamentous fungi; classes I, II, and IV are common to yeasts and filamentous fungi, while classes III, V, VI, and VII are present only in the latter (Bowen et al. 1992; Choquer et al. 2004; Roncero 2002; Ruiz-Herrera et al. 2001). Systematic mutagenesis of each CHS gene (chs) has been undertaken in several fungal species, including $\mathrm{Neu}$ rospora crassa on four genes (Beth-Din and Yarden 2000; Din and Yarden 1994; Din et al. 1996; Yarden and Yanofsky 1991), Fusarium oxysporum and Aspergillus nidulans on six genes (Borgia et al. 1996; Culp et al. 2000; Horiuchi et al. 1999; Madrid et al. 2003; Martin-Udiroz et al. 2004, 2008; Motoyama et al. 1994: Specht et al. 1996), Aspergillus fumigatus and Wangiella dermatitidis on seven genes (Aufauvre-Brown et al. 1997; Liu et al. 2004; Mellado et al. 1996, 2003; Wang et al. 1999, 2001; Zheng et al. 2006), and Ustilago maydis on eight genes (Garcera Teruel et al. 2004; Gold and Kronstad 1994; Xoconostle-Cazares et al. 1996, 1997). The single deletion of a class I or II gene did not lead to a marked phenotype in the latter, except the class I mutant in $N$. crassa, in which uninucleate conidia were unable to germinate (Beth-Din and Yarden 2000). CHS classes III, V, VI, and VII are mold specific, suggesting they might play an important role in hyphal growth. Our previous work showed that $B$. cinerea has at least eight CHS genes (Choquer et al. 2004). Several mutants, including class I Bcchs1 (Soulié et al. 2003), class III Bcchs3a (Soulié et al. 2006), class IV Bcchs4, class VI Bcchs6, and class VII $B c c h s 7$, were constructed by reverse genetics. Mutation in the Bcchs6 gene was revealed to be lethal (M.-C. Soulié, unpub- 
lished data). These mutants are interesting for cell-wall studies in particular, because the cell-wall composition of $B$. cinerea wild type has been described (Cantu et al. 2009). Interesting phenotypic traits of mutant Bcchs $3 a$ have been reported in other class III mutants of filamentous fungi, including unchanged growth rate in liquid medium. Drastic reduced growth on solid medium with highly branched mycelia was observed, suggesting a preferential role of class III CHS in apex extension and hyphal organization. On the other hand, some characteristics are specific to the $B$. cinerea $B c c h s 3 a$ mutant, i.e., the presence of a thick extracellular matrix (ECM) around the hyphal tips and a reduced virulence on $V$. vinifera and A. thaliana leaves. Microscopic in planta examinations showed empty hyphal structures resembling ghost cells. Soulié and associates (2006) suggested that this mutant could be more susceptible to plantdefense molecules than the wild-type strain Bd90, due to changes in the cell-wall structure resulting from lack of BcCHS3a protein.

Plant defense against invading pathogens is governed by a complex web of signaling pathways leading to activation of subsets of defense effectors. Three major signaling pathways are mediated by phytohormones salicylic acid (SA), jasmonic acid (JA), and ethylene (ET) (Glazebrook 2005). The JA- and ETmediated pathways were shown to establish a basic level of defense against necrotroph pathogens like $B$. cinerea (Diaz et al. 2002; Ferrari et al. 2003; Glazebrook 2005; Thomma et al. 1999). Soulie and associates (2006) found that the BcCHS3a protein is not necessary to protect the pathogen from defense controlled via JA and ET. However, the Bcchs $3 a$ mutant could be more sensitive to other defense mechanisms known to be triggered by pathogens (Hammond-Kosack and Jones 1996), such as reinforcement of cell walls, production of antimicrobial compounds (phytoalexins, phenolic compounds) or the oxidative burst. The role of the phytoalexin camalexin in resistance of $A$. thaliana to $B$. cinerea has been well studied (Denby et al. 2004; Ferrari et al. 2003; Kliebenstein et al. 2005). A relationship between in vitro camalexin susceptibility and virulence of the fungus on ecotype Col-0 has been established by Kliebenstein and associates (2005), demonstrating that camalexin tolerance of B. cinerea was isolate-dependant. Two Arabidopsis mutants, pad2 and pad3, isolated on the basis of reduced accumulation of camalexin after inoculation with bacterial pathogens (Glazebrook and Ausubel 1994), showed higher susceptibility to B. cinerea (Chassot et al. 2008; Ferrari et al. 2003; van Baarlen et al. 2007).

In this work, we further searched for the reasons why Bcchs $3 a$ disruption alters $B$. cinerea virulence. We then conducted a detailed analysis of the $B$. cinerea mutant virulence compared with wild-type $\mathrm{Bd} 90$ on a set of $A$. thaliana mutants defective in various defense responses. Our results support the proposal that lack of a functional Bcchs3a CHS gene in B. cinerea is responsible for altered adhesion and overstimulation of host plant immunity.

\section{RESULTS}

\section{Mutant $B c c h s 3 a$ is greatly impaired \\ in lesion formation on Arabidopsis ecotype Col-0.}

The Bcchs $3 a$ mutant defective in class III CHS has reduced virulence on host plants (Soulié et al. 2006), suggesting an increased susceptibility of this cell-wall mutant towards plant defense molecules or its incapacity to elude the defense mechanisms of the host. To investigate this hypothesis, we first compared the lesion development of wild-type strain Bd90 with that of the Bcchs $3 a$ mutant on leaves of A. thaliana ecotype Col-0 (Fig. 1A). We applied young mycelium plugs on detached leaves and daily recorded the number of leaves showing spreading lesions. A typical lesion of B. cinerea on Arabidopsis leaves (Fig. 1A) consists of a maceration spreading around the mycelium plug. The histogram shown in Figure 1A shows the symp-

\section{A Col-0}
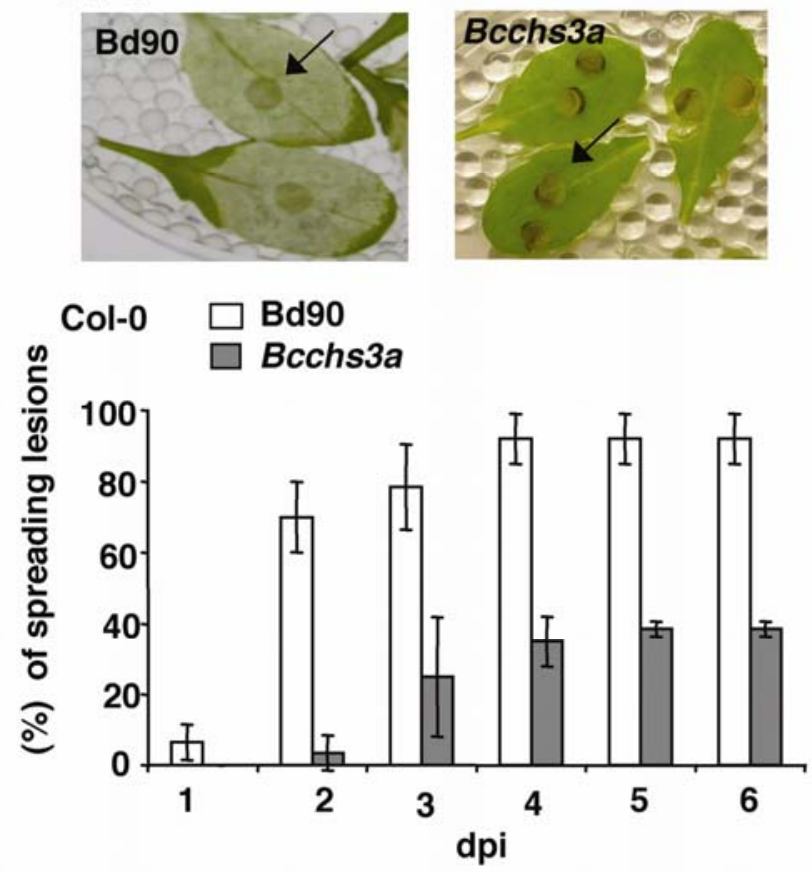

B Pad3
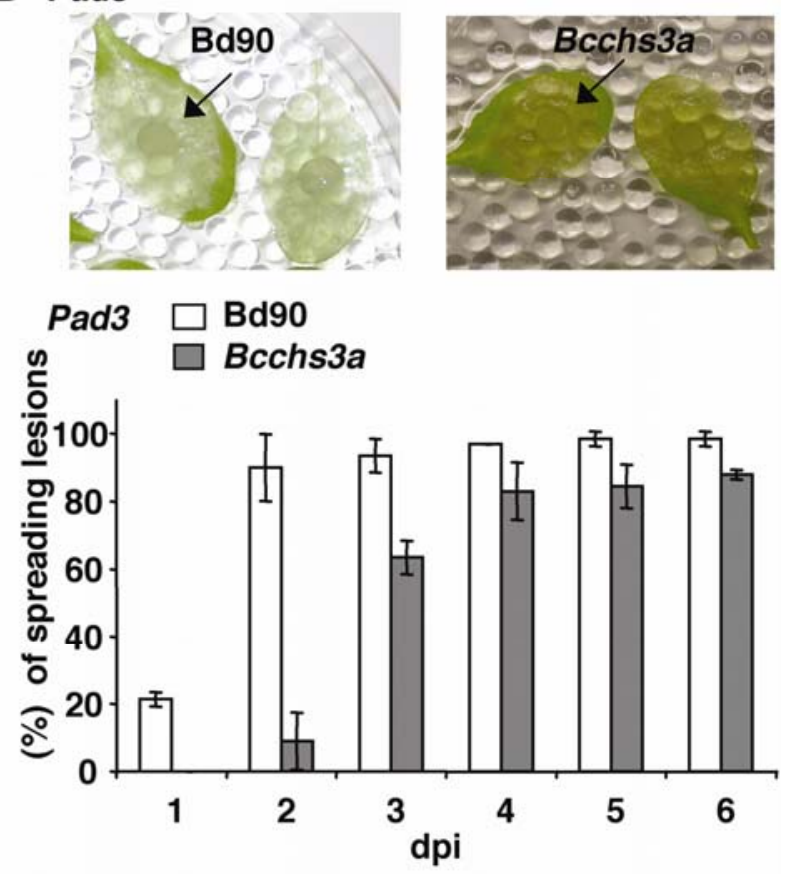

Fig. 1. Disease development of wild-type strain Bd90 and mutant Bcchs3a on Arabidopsis thaliana leaves. A, Col-0 and B, Pad3 leaves were inoculated with mycelium plugs, and disease development was followed for up to 6 days postinoculation (dpi). Spreading lesions (3 dpi) of wild-type strain Bd90 are shown on the left and mutant Bcchs3a-inoculated leaves without spreading lesions are shown on the right. The graphs show the percentages of leaves with spreading lesions up to $6 \mathrm{dpi}(n=30)$. A lesion was considered spreading when the lesion size reached $0.4 \mathrm{~cm}^{2}$. Bars represent the means of two experiments $( \pm$ standard deviation). Spreading lesions are shown for wild-type strain Bd90 (3 dpi) and mutant Bcchs $3 a$ (6 dpi). 
tom evolution as a function of time. For the wild-type strain, $70 \%$ of inoculated Col-0 leaves displayed spreading lesions after 2 days postinoculation (dpi), reaching almost $100 \%$ after 4 days. In contrast, mutant Bcchs $3 a$ generated spreading lesions on less than $5 \%$ of Col- 0 leaves after 2 dpi. After 4 days, this percentage reached $35 \%$ and did not increase further, even after 6 dpi. Therefore, in $65 \%$ of leaves inoculated with the Bcchs $3 a$ mutant, no spreading lesions occurred. Instead, necrotic spots were visible underneath the mycelium plug (Figs. 1A and 4). We also compared the size of lesions caused by both fungal strains. We measured lesion size daily and calculated the lesion growth rate $\left(\mathrm{cm}^{2} \mathrm{~h}^{-1}\right)$ on Col-0 leaves. The histogram in Figure 2 shows that the growth rate is not statistically different between Bd90 $\left(0.03 \mathrm{~cm}^{2} \mathrm{~h}^{-1}\right)$ and Bcchs $3 a\left(0.034 \mathrm{~cm}^{2} \mathrm{~h}^{-1}\right)$. Thus, the mutant Bcchs3a generates a drastically reduced number of spreading lesions on Col-0 leaves. However, if lesion formation occurs, the mutant spreads throughout the plant to the same extent as Bd90.

\section{Mutant Bcchs3a is virulent on pad3 leaves of Arabidopsis.}

$B$. cinerea is known to be confronted by high amounts of reactive oxygen species (ROS) at the infection site, and it has been shown that the pathogen is well adapted to the oxidizing environment in the host tissue (Mayer et al. 2001; Schouten et al. 2002). A defect in the cell wall of $B$. cinerea leading to increased sensitivity to active oxygen species would, therefore, be deleterious for the pathogen. In addition, plant secondary metabolites like flavonols and, in particular phytoalexins (camalexin), influence lesion size in infected tissue (Denby et al. 2004; Ferrari et al. 2003; Kliebenstein et al. 2005) and may be more efficient towards a fungal cell-wall mutant. We thus tested the sensitivity of $A$. thaliana mutants altered in oxidative burst (AtrbohDF), flavonols (Atfah1-7tt5), or camalexin production (pad3 and pad2) to wild-type strain Bd90 and mutant Bcchs3a. The susceptibility of AtrbohDF and Atfahl-7tt5 mutant leaves to infection was the same as on Col-0 for both fungal strains (data not shown). With the pad3 mutant (Fig. 1B), we found that, 2 dpi with Bd90 strain, $90 \%$ of the leaves displayed spreading lesions. Mutant Bcchs3a also caused $90 \%$ of spreading lesions but only after $4 \mathrm{dpi}$, indicating a 2-day delay in the infection process. Mutant Bcchs $3 a$ showed the same maceration phenotype as Bd90 (Fig. 1B). A similar phenotype was found on $A$. thaliana mutant pad2 (data not shown). We

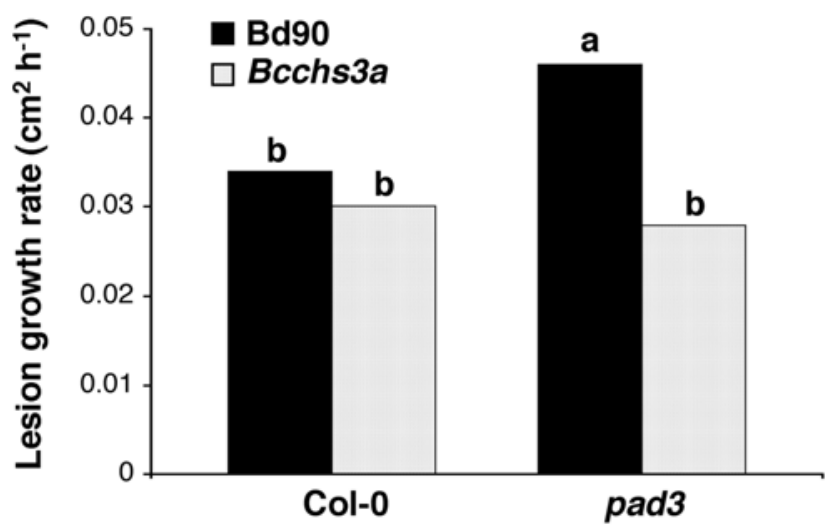

Fig. 2. Lesion growth rate of wild-type strain Bd90 and mutant Bcchs $3 a$ on Col-0 and pad3 Arabidopsis leaves. The lesion size on each diseased leave was measured over several days and the lesion growth rate on each leaf was measured $\left(\mathrm{cm}^{2} \mathrm{~h}^{-1}\right)$. For strain Bd90, 28 diseased Col-0 and 29 diseased pad3 leaves were examined; for mutant Bcchs $3 a$ 11, diseased Col-0 and 24 diseased pad3 leaves were examined. Bars represent the mean of the lesion growth rates and different letters indicate significantly unequal rates (Kruskal-Wallis test, $P=0.05$ ). The experiment was conducted twice and similar results were obtained. calculated the lesion growth rate in pad3 leaves for both strains (Fig. 2). The lesions of Bd90 strain spread significantly faster $\left(0.046 \mathrm{~cm}^{2} \mathrm{~h}^{-1}\right)$ than those of mutant Bcchs $3 a\left(0.028 \mathrm{~cm}^{2}\right.$ $\mathrm{h}^{-1}$ ) (Kruskal-Wallis test, $P=0.05$ ). A comparison of these results with those obtained on Col-0 leaves indicated that Bd90 lesions spread significantly faster on pad3 leaves (KruskalWallis test, $(P=0.05)$. This was not the case for the lesions caused by the Bcchs $3 a$ mutant. These results suggest that wildtype $\mathrm{Bd} 90$ is a camalexin-susceptible isolate. In leaves defective in production of camalexin, the mutant Bcchs $3 a$ is rescued in the capacity to cause spreading lesions and the wild-type strain has increased virulence.

\section{In vitro susceptibility of the mutant $B c c h s 3 a$ towards camalexin.}

Our results suggest that the presence of camalexin in Arabidopsis Col-0 leaves hinders the formation of spreading lesions by mutant $B c c h s 3 a$. Camalexin could be more toxic to the cellwall mutant Bcchs $3 a$ than to wild-type strain Bd90, arresting
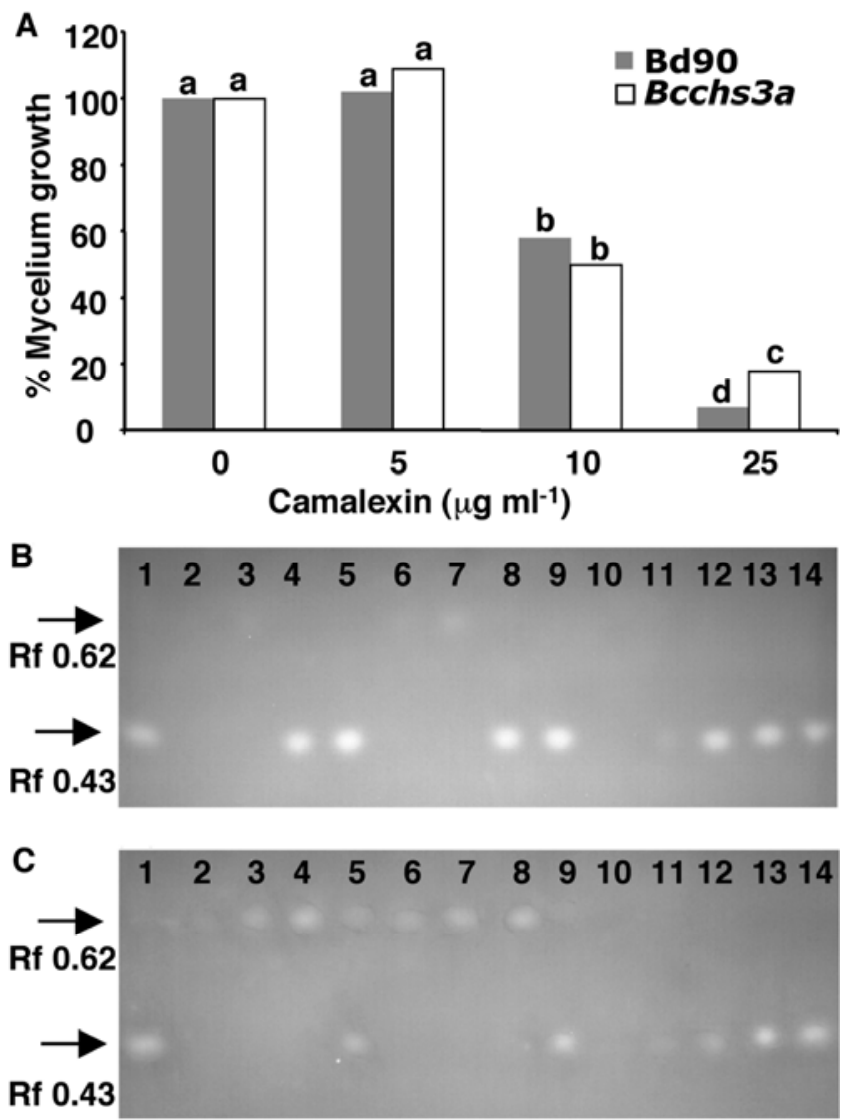

Fig. 3. In vitro growth of wild-type strain Bd90 and mutant $B c c h s 3 a$ in the presence of different camalexin concentrations in liquid culture. A, Inhibition of growth was followed by measurment of the absorbance at $405 \mathrm{~nm}$ in the presence of $0,5,10$, and $25 \mu \mathrm{g}$ of camalexin per milliliter. Growth inhibition is indicated at 4 days postinoculation. Values in the absence of camalexin are indicated by $100 \%$. Different letters indicate significantly different growth rates from one another at $P=0.05$. B and $\mathbf{C}$, Presence of camalexin in incubation mixtures of wild-type strain Bd90 and mutant $B c c h s 3 a$. Microtitre-plate incubation mixtures $(30 \mu \mathrm{l})$ were separated by silica thin-layer chromatography, and camalexin was visualized by its blue fluorescence under an ultraviolet lamp. Incubation mixtures are shown after 4 (B) and 7 days (C) of incubation. Lanes 1 and 14 show purified blue fluorescent camalexin $(\mathrm{Rf}=0.43)$. Incubation mixtures of wild-type strain $\mathrm{Bd} 90$ are shown in lanes 2 to 5, of mutant Bcchs $3 a$ in lanes 6 to 9 , and incubation mixtures without fungi in lanes 10 to 13 . Camalexin concentrations were $0 \mu \mathrm{g} \mathrm{ml}^{-1}$ (lanes 2, 6, and 10), $5 \mu \mathrm{g} \mathrm{ml}^{-1}$ (lanes 3, 7, and 11), $10 \mu \mathrm{g} \mathrm{ml}^{-1}$ (lanes 4, 8, and 12), and $25 \mu \mathrm{g} \mathrm{ml}^{-1}$ (lanes 5, 9, and 13). A second spot of yellow fluorescence is visible at $\mathrm{Rf}=0.62$. 
mutant growth before the onset of lesion spreading. To test this hypothesis, we measured fungal growth in vitro in the presence of increased camalexin (a gift from J. Glazebrook) concentrations corresponding to $0,5,10,25$, and $50 \mu \mathrm{g} \mathrm{ml}^{-1}$ in liquid Czapek glucose medium (incubation mixture) in a microtiter plate. Growth was recorded at 4 dpi by measuring absorbance at $405 \mathrm{~nm}$, and growth inhibition in the presence of camalexin is illustrated in Figure 3A. No significant inhibition occurred at $5 \mu \mathrm{g} \mathrm{ml}^{-1}$ for either strain. A significant inhibition of mycelium growth was found for both strains at $10 \mu \mathrm{g} \mathrm{m}^{-1}$ ( $\Delta$ absorbance $=-0.20$; standard error $[\mathrm{SE}]=0.05$ for $\mathrm{Bd} 90$ and $B c c h s 3 a$; $P<0.01)$ without difference between the strains. At $25 \mu \mathrm{g} \mathrm{ml}^{-1}$, growth reduction was significant for both strains but significantly higher for wild-type strain $\mathrm{Bd} 90(\Delta$ absorbance $=-0.45$; $\mathrm{SE}=0.05 ; P<0.01)$ than for mutant Bcchs3a ( $\Delta$ absorbance $=$ $-0.25 ; \mathrm{SE}=0.05 ; P<0.01)$. At camalexin concentrations of 50 $\mu \mathrm{g} \mathrm{ml} \mathrm{l}^{-1}$, growth of both strains was totally inhibited (data not shown). These results confirm that wild-type strain $\mathrm{Bd} 90$ is susceptible to camalexin in vitro. In order to know if the fungus was killed in the presence of camalexin, we inoculated malt agar plates with the fungus present in the incubation mixtures (8 dpi). At all camalexin concentrations tested, both $B$. cinerea strains recovered normal growth on the malt medium. Altogether these results demonstrate that mutant $B c c h s 3 a$ is not more susceptible towards camalexin than wildtype strain Bd90. It is even slightly more resistant at elevated concentrations of this compound. In addition, the effect of camalexin on $B$. cinerea is likely fungistatic rather than fungitoxic up to $25 \mu \mathrm{g} \mathrm{ml}{ }^{-1}$.

We then compared the capacity of mutant Bcchs $3 a$ and wild-type strain Bd90 to detoxify camalexin. For this purpose, we used the microtiter plate growth assay described above in combination with thin-layer chromatography, followed by camalexin visualization by fluorescence. Samples of the fungal incubation mixtures (Bd90 or Bcchs $3 a$ ) containing different camalexin concentrations $\left(0,5,10\right.$, and $\left.25 \mu \mathrm{g} . \mathrm{ml}^{-1}\right)$ were examined 4 and 7 dpi in this way. In Figure $3 B$ and $C$, we can observe that camalexin $(\mathrm{Rf}=0.43)$ disappeared over time in the presence of the fungal strains. Moreover, a new fluorescent compound with a higher $\mathrm{Rf}$ value $(\mathrm{Rf}=0.62)$ appeared in both fungal incubation mixtures $7 \mathrm{dpi}$. The appearance of this compound was linked to fungal growth, and the fluorescence intensity was strongest at $10 \mu \mathrm{g} \mathrm{ml}^{-1}$ camalexin, when fungal growth was partially inhibited and camalexin in the incubation mixture disappeared. Thus, there was a correlation between camalexin disappearance and appearance of the yellow fluorescent spot. For all observations, no obvious difference was found between the two strains Bd90 and Bcchs3a.

\section{Camalexin accumulation is correlated to a decrease in Bcchs $3 a$ mutant virulence.}

To test whether camalexin accumulated to higher amounts at $B c c h s 3 a$ infection site in comparison to $\mathrm{Bd} 90$, we measured camalexin concentrations in Col-0 leaves inoculated with mycelium plugs of the two strains. Camalexin was determined in leaf disks collected after 3 dpi. For wild-type strain Bd90, we quantified camalexin in an extract of the healthy area adjacent to macerated tissue (+2 mm) (Fig. 4). According to Kliebenstein and associates (2005), a dramatic increase in camalexin content takes place in the healthy region immediately surrounding the lesion. For mutant Bcchs $3 a$, camalexin was quantified in extracts from leaf disks sampled directly below the mycelium plug containing necrotic spots (Fig. 4). We took into consideration only the area surrounding these necrotic spots (Fig. 4, outlined in red). Camalexin content after inoculation with $\mathrm{Bd} 90$ was $1 \mathrm{ng} \mathrm{mm}^{-2}$. This amount did not stop fungal growth.
Similar amounts were found for the wild-type B0510 isolate used by Chassot and associates (2008) and Stefanato and associates (2009). Camalexin content after Bcchs3a infection was $19 \mathrm{ng}$ per square millimeter, while in mock-inoculated leaves, the concentration reached only $0.04 \mathrm{ng} \mathrm{mm}^{-2}$. These values are all significantly different from one other (Mann-Whitney test, $P=0.05)$. Thus, there were higher amounts of camalexin at infection sites of Bcchs $3 a$ compared with those of wild-type strain Bd90. This result could be due to overexpression of camalexin biosynthesis genes. The cytochrome P450 cyp71B15 enzyme encoded by the PAD3 gene (Zhou et al. 1999) catalyzes the final step in camalexin biosynthesis downstream from indole-3 acetaldoxime, which is synthesized from tryptophan (Schuhegger et al. 2006). Thus, expression of the $P A D 3$ gene can mirror the accumulation of camalexin. PAD3 gene expression was monitored using real-time reverse transcription-polymerase chain reaction (RT-PCR) in Bcchs $3 a$ and Bd90-infected leaves of $A$. thaliana ecotype Col-0. This study was performed 18 and $48 \mathrm{~h}$ after inoculation (hpi), with mycelium plugs or conidia suspensions on detached leaves. $P A D 3$ gene expression in infected tissues was expressed per nanogram of $B$. cinerea cDNA (Fig. 5). We observed an induction of the $P A D 3$ gene in leaves infected with mycelium plugs whatever the fungal strain or the incubation time. PAD3 geneexpression levels in conidia-infected tissues were very low (Fig. 5). At $18 \mathrm{hpi}$, the expression levels were two to four times higher in the tissues infected with the Bcchs3a mutant than with wild-type Bd90. On the other hand, we observed a decrease in PAD3 gene expression for both strains 48 hpi. Thus, it is likely that the increased camalexin accumulation observed in Bcchs3a mycelium-infected tissues is due to enhanced transcriptional activation of the PAD3 gene involved in camalexin biosynthesis.
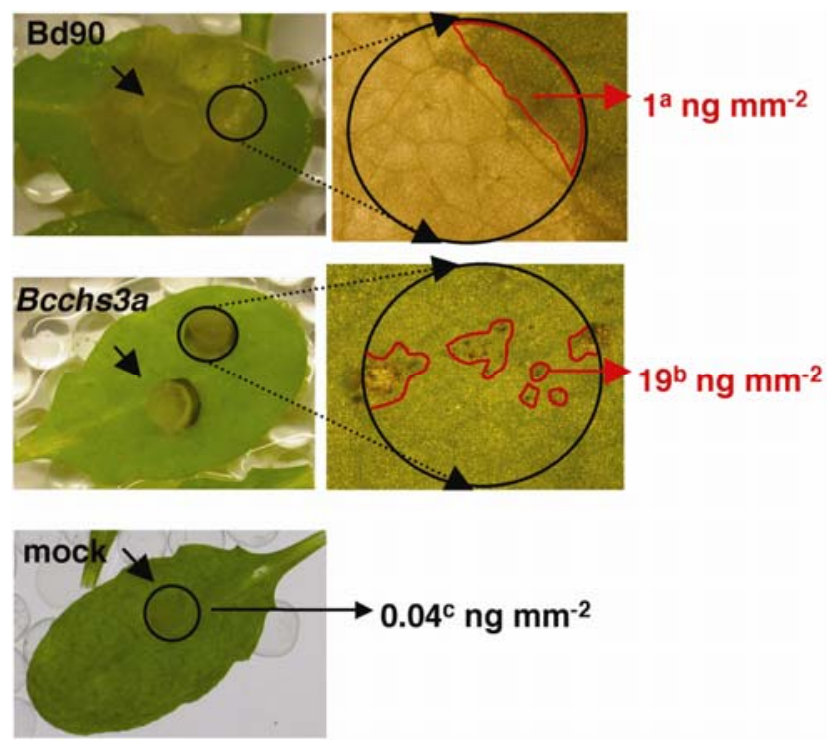

Fig. 4. Camalexin accumulation at wild-type strain $\mathrm{Bd} 90$ and Bcchs3a infection sites in ecotype Col-0 Arabidopsis. Cut leaves were inoculated on the upper side with mycelium plugs, and symptoms are shown 3 days postinoculation; closeups of symptoms are shown on the right. For Bd90, only the tissue adjacent to the maceration was used for camalexin extraction (area surrounded in red). For Bcchs $3 a$ and mock inoculation, the whole leaf disk (black circle) was used for phytoalexin extraction. Camalexin concentrations are expressed in nanograms per square millimeter of surface area encircled in red on the closeups $\left(33 \mathrm{~mm}^{2}\right.$ for Bd 90 and $8.8 \mathrm{~mm}^{2}$ for $\left.B c c h s 3 a\right)$. Different letters indicate significantly unequal values (Mann-Whitney test, $P=0.05$ ). The experiment was conducted four times and similar results were obtained. Arrowheads indicate mycelium plugs. 
The mycelium of Bcchs $3 a$ mutant is impaired in adhesion.

Virulence tests performed on pad3 leaves showed that $B c c h s 3 a$ mutant is able to form spreading lesions in the absence of camalexin. Nevertheless, the lesions appeared 2 days later compared with those of Bd90 (Fig. 1B). This delay might be due to a weak adhesion of Bcchs3a mycelium plugs to the plant surface. To investigate this hypothesis we inoculated Col0 and pad3 leaves with $\mathrm{Bd} 90$ and Bcchs $3 a$ mycelium plugs, turned over the leaves 0 and $6 \mathrm{hpi}$, and counted the detached mycelium plugs. Out of 20 mycelium plugs tested for each timepoint and each strain, we found, on Col-0 leaves, six (seven on pad3 leaves) Bd90 plugs detached at 0 hpi and 0 plugs (three on pad3 leaves) at $6 \mathrm{hpi}$. On the contrary, for Bcchs $3 a$ mutant, 16 mycelium plugs fell off the Col-0 and pad3 leaves at 0 hpi and 15 plugs ( 17 on pad 3 leaves) at $6 \mathrm{hpi}$. These results clearly show a better adhesion of wild-type mycelium to the leaf surface than for Bcchs $3 a$ mutant. Poor adhesion of mycelium might lead to delayed penetration and lesion formation. We then used a penetration test on onion epidermis strips (Gourgues et al. 2004) inoculated with wild-type strain Bd90 and mutant Bcchs3a mycelium plugs. Observations were performed after 15 and $24 \mathrm{~h}$ of incubation (Fig. 6). At $15 \mathrm{hpi}$, the wild-type strain had formed long hyphae growing on the epidermis surface before penetrating. At this timepoint, many infectious hyphae were observed inside the tissue (Fig. 6A). On the contrary, Bcchs $3 a$ mutant had formed only a few hyphae growing on the surface without penetration (Fig. 6B). At $24 \mathrm{hpi}$, Bcchs $3 a$ mycelia had formed some complex structures with agglomerated hyphae (Fig. 6C) on the host surface, and we observed infectious hyphae inside the tissues (Fig. 6D). Thus, we conclude that Bcchs $3 a$ mycelium adheres poorly to

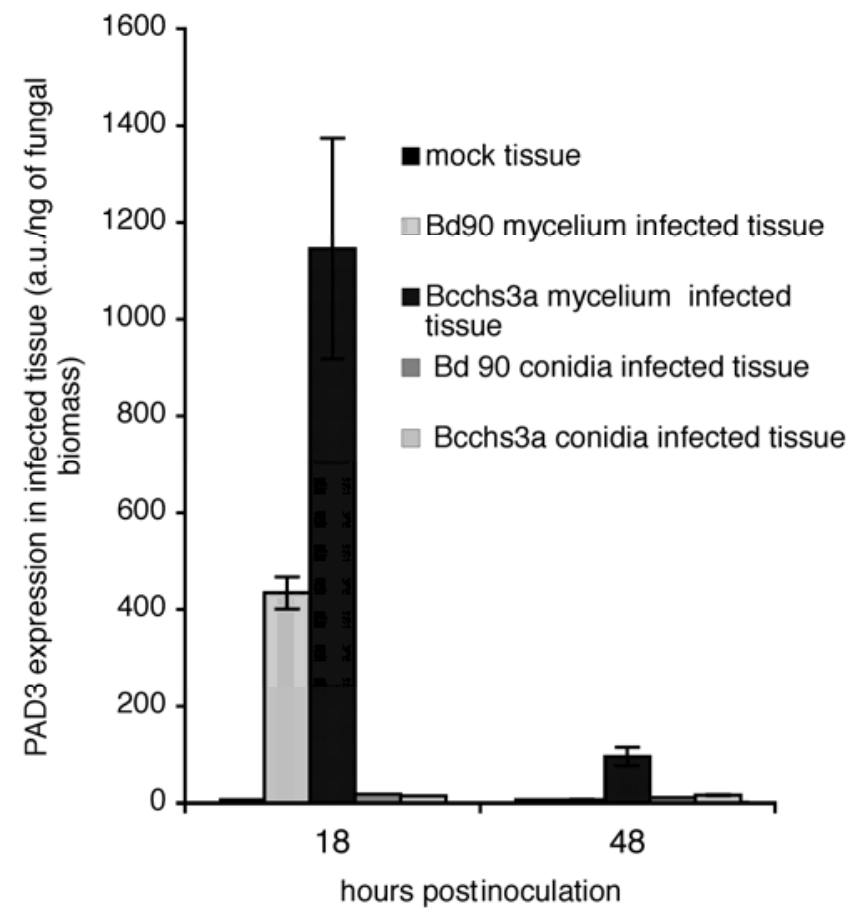

Fig. 5. PAD3 mRNA accumulation in leaves of Arabidopsis thaliana ecotype Col-0 inoculated with mycelium or conidia suspension of Bd90 wildtype strain or Bcchs3a mutant. Expression levels of PAD3 gene were determined at 18 and $48 \mathrm{~h}$ postinoculation and were quantified by real-time polymerase chain reaction. Transcript levels were normalized to the plant reference EF1, and Botrytis cinerea was quantified in infected tissue with the fungal reference gene actin. $P A D 3$ transcript levels were then quantified in arbitrary units (a.u.) per ng of $B$. cinerea biomass present in infected leaves. Data are the means of triplicates ( \pm standard deviation), and the experiment was repeated twice with similar results. the plant surface and that its penetration is delayed. These observations could explain the delay in initiation of lesion formation observed on pad3 leaves.

\section{The Bcchs3a mutant is virulent} when inoculated via conidia suspensions.

As all virulence tests in this study were performed with mycelium plugs as inoculum, we determined the expression level of Bcchs $3 a$ gene in Bd90 mycelium. For this purpose, Bd90 mycelium was grown in vitro for 3 days on cellophane sheets applied on malt extract (ME) solid medium, the actively growing hyphae were harvested, and RNA was extracted. We chose a 3-day-old mycelium in accordance with the age of the mycelium used as inoculum. The expression of $B c c h s 3 a$ gene was analyzed by real-time RT-PCR. We observed a strong expression of this gene $(21 \pm 9$ arbitrary units at $3 \mathrm{dpi}$ ), consistent with an essential role for BcCHS3a at early stages of infection following mycelium inoculation. In nature, however, $B$. cinerea has a variety of modes of attack, such as mycelia or conidia (Choquer et al. 2007), and we further investigated the expression of $B c c h s 3 a$ gene in conidia, frequently used as inoculum in virulence assays (Williamson et al. 2007). Conidia suspensions $\left(10^{9}\right.$ conidia $\left.\mathrm{ml}^{-1}\right)$ were spread on a cellophane sheet in petri dishes and, after 5, 10, 18 , and $72 \mathrm{~h}$ of incubation, total RNA was extracted. The expression of Bcchs $3 a$ gene was followed by real-time RTPCR (Fig. 7). During conidia germination, we observed only a weak accumulation of Bcchs $3 a$ transcripts after $10 \mathrm{~h}$ of incubation. A strong increase in Bcchs $3 a$ gene expression was apparent after $18 \mathrm{~h}$ of incubation that was maintained until $72 \mathrm{~h}$. These results indicate that $B c c h s 3 a$ is probably not expressed in germinated conidia before and during tissue penetration, which occurs as early as 10 hpi (Soulié et al. 2006). Consequently, the enzyme BcCHS3a should not be required at early stages of infection if conidia suspensions are inoculated. Thus,
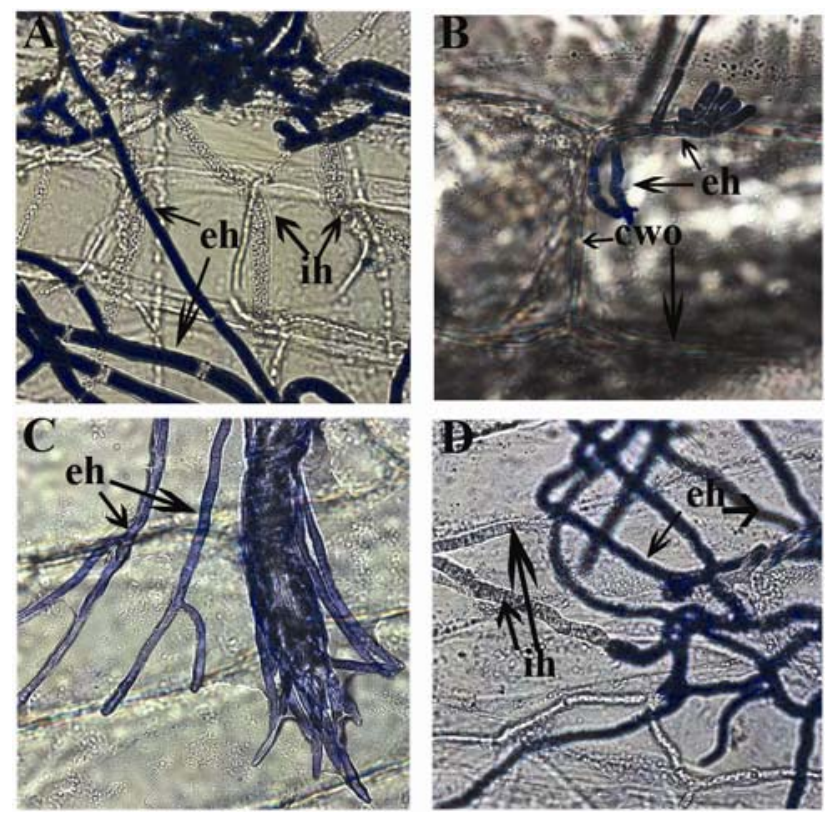

Fig. 6. Onion penetration assay with $\mathbf{A}, \mathrm{Bd} 90$ wild-type strain and $\mathbf{B}, \mathbf{C}$, and $\mathbf{D}, B$ cchs $3 a$ mutant. Inverted mycelium plugs (6 $\mathrm{mm}$ in diameter) of the two strains were applied on the hydrophobic side of onion epidermis and were maintained at $21^{\circ} \mathrm{C}$. After incubation for 15 (A and B) and $24 \mathrm{~h}$ $(\mathrm{C}$ and $\mathrm{D})$, fungal cells were stained with cotton blue. Infection structure formation (stained in blue) and in planta growth (not stained) were observed. More than 50 infection sites were analyzed. External hyphae are indicated by eh, internal hyphae by ih, and the onion epidermis cell wall by cwo. Photographs were taken at $150 \times$ magnification. 
we conducted virulence tests using conidia suspensions of Bd90 or Bcchs $3 a$ mutant on A. thaliana ecotype Col-0 as well as bean and grapevine leaves. Results showed that, whatever the fungal strain or the host plant, all the inoculated leaves displayed typical symptoms of maceration (data not shown). We also analyzed camalexin accumulation in $A$. thaliana leaves inoculated with $\mathrm{Bd} 90$ or Bcchs $3 a$ conidia. The same amounts of camalexin were obtained for both strains (1 ng per square millimeter of leaf surface). These results indicate that BCCHS3a plays an essential role only during mycelium attack and that different mechanisms are involved in the $B$. cinerea conidia or mycelium infection process.

\section{The ECM of Bcchs3a mutant.}

In our previous work on the characterization of $B c c h s 3 a$ mutant, microscopic analysis revealed the presence of a thick ECM around hyphae (Soulié et al. 2006), and the use of specific antibodies allowed us to conclude that the ECM did not contain any $\beta 1-3$ glucan, 1-4 glucan, or chitin. In this study, we analyzed the ECM composition in neutral hexoses of two strains, Bd90 wild type and mutant Bcchs3a (Table 1). The components known to be predominant in the ECM are reinforced up to $30 \%$ in mutant Bcchs3a; mannose and galactose contents are enhanced by 58 and $48 \%$, respectively, compared with wild-type strain Bd90.

We also investigated whether the thick ECM observed around $B c c h s 3 a$ hyphae was present in germinating conidia. In our previous work, we found that the Bcchs3a ECM appeared out of focus when stained with calcofluor white. Using this fluorescent staining that binds to nascent microfibrils of chitin, no morphological difference was observed between the wildtype strain Bd90 and Bcchs3a mutant conidia (Fig. 8). This

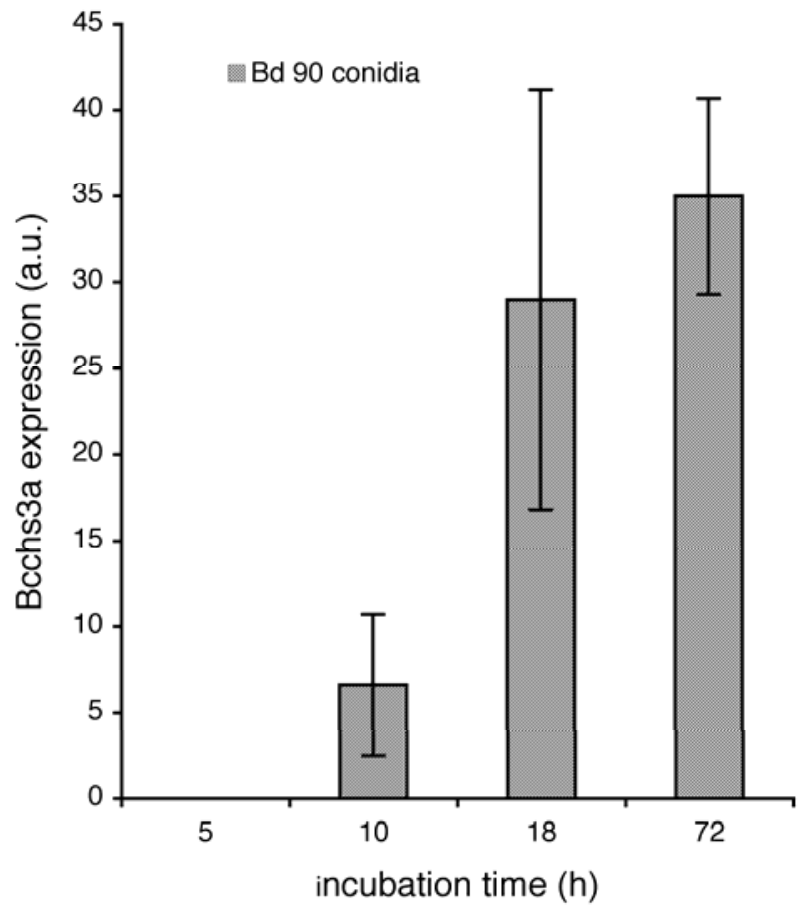

Fig. 7. Expression of the Bcchs3a gene during conidia germination and mycelium growth of wild-type strain Bd90. Expression levels of the $B c c h s 3 a$ gene were quantified after 5,10 , and $18 \mathrm{~h}$ of incubation for conidia germlings and after $72 \mathrm{~h}$ for conidia and mycelium, using quantitative reverse transcription-polymerase chain reaction and were normalized to the transcript level of the $B$. cinerea reference gene actin. Data are expressed as mean normalized expression in arbitrary units (a.u.) and are the means of triplicates ( \pm standard deviation). The experiment was repeated twice with similar results. means that this thick Bcchs3a ECM is present on mycelium but absent on conidial germlings.

\section{DISCUSSION}

The fungal cell wall is a dynamic structure that maintains cell shape and integrity in the face of environmental stress. In pathogenic fungi, the cell wall is the first element that interacts with the host surface and mediates the adhesion of cells to one another and the host. Moreover, the fungal cell wall is a reservoir of molecules involved in host recognition, suggesting that changes in fungal wall structure can be perceived by plant cells at early stages of infection. CHS enzymes participate in the biosynthesis of the fungal cell wall. Their role during vegetative development is well documented, but little is known about their function during pathogenic growth in planta (Madrid et al. 2003; Martin-Urdiroz et al. 2008; Werner et al. 2007). In a previous study, we showed that a class III CHS, BcCHS3a, is involved in hyphal tip elongation of $B$. cinerea and is required in the virulence of the fungus on its major host plant, grapevine, as well as on the model plant Arabidopsis thaliana. In the present work, we demonstrated that the absence of a functional Bcchs3a gene in the mycelium causes a drastic effect on accumulation of camalexin, a phytoalexin known to be produced by $A$. thaliana in response to avirulent pathogens and to contribute to resistance to $B$. cinerea (Denby et al. 2004; Ferrari et al. 2003; Kliebenstein et al. 2005).

Accumulation of camalexin in response to the Bcchs $3 a$ mutant is likely due to an increased production of this compound and not to a lack of detoxification. The enhanced camalexin amount at Bcchs $3 a$ mutant infection sites (20 times more than the wild-type strain) is probably the consequence of an overinduction of $P A D 3$ gene involved in camalexin biosynthesis. Recent papers published by Ferrari and associates (2007) and Chassot and associates (2008) have shown that the $P A D 3$ gene was induced by $B$. cinerea attack. In this paper, we show that both strains, wild-type strain Bd90 and mutant Bcchs3a, metabolize camalexin, whereby a new fluorescent compound appears in the incubation mixture. Stefanato and associates (2009) have demonstrated a camalexin detoxification mechanism in $B$. cinerea involving the $\mathrm{ABC}$ transporter

Table 1. Extracellular matrix composition in neutral hexoses of $\mathrm{Bd} 90$ wild-type and mutant $B c c h s 3 a$ mycelium

\begin{tabular}{lcccc}
\hline Strains & Neutral hexoses $^{\mathbf{a}}$ & Mannose $^{\mathbf{b}}$ & Galactose $^{\mathbf{b}}$ & Glucose $^{\mathbf{b}}$ \\
\hline Bd90 wild type & $2.94 \pm 0.86$ & $0.94 \pm 0.01$ & $0.37 \pm 0.09$ & 1 \\
Mutant Bcchs3a & $4.30 \pm 0.60$ & $2.21 \pm 0.19$ & $0.70 \pm 0.05$ & 1 \\
\hline
\end{tabular}

a In milligrams per gram of fresh weight.

${ }^{\mathrm{b}}$ Molar ratio.

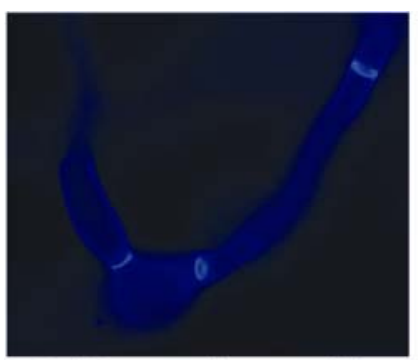

Bd90 germling conidia

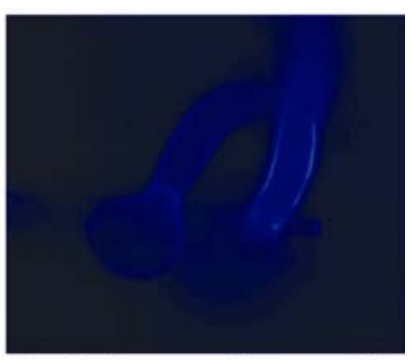

$B c c h s 3 a$ germling conidia
Fig. 8. Microscopy analysis of germling conidia from Bd 90 wild-type strain and Bcchs $3 a$ mutant. Conidia were incubated for $7 \mathrm{~h}$ in potato dextrose broth diluted by half at $21^{\circ} \mathrm{C}$ and were observed after Calcofluor white staining. Photographs were taken at $500 \times$ magnification. 
BcatrB, which functions in the efflux of fungitoxic compounds. Other phytopathogenic fungi were able to degrade and detoxify camalexin (Pedras and Ahiahonu 2004), such as Rhizoctonia solani a pathogen of Camelina sativa (Pedras and Kahn 1997, 2000) and Sclerotinia sclerotiorum, which causes stem-rot disease in a vast range of plants (Pedras and Ahiahonu 2002). According to these authors, the resulting biotransformation products were significantly less inhibitory than camalexin itself. In this study, we showed for the first time that $B$. cinerea is most likely able to deactivate camalexin via a still-uncharacterized metabolic process in addition to exporting camalexin via an ABC transporter (Stefanato et al. 2009).

We did not find an increased susceptibility of the Bcchs $3 a$ mutant to camalexin in vitro, which could have explained its loss in virulence. The cell-wall mutant is even slightly more resistant towards elevated camalexin concentrations. In our previous paper, we revealed the ECM around Bcchs $3 a$ mutant hyphae is considerably more important compared with that of wild-type strain Bd90 (Soulié et al. 2006). This ECM in $B$. cinerea, first described by Doss and associates (1995), could protect the Bcchs $3 a$ mutant against antimicrobial compounds. Another filamentous fungus, the human pathogen Aspergillus fumigatus, also produces a matrix, under aerial conditions, that cohesively bonds hyphae into a contiguous sheath (Beauvais et al. 2007). These authors have shown that Aspergillus fumigatus aerial colonies were more resistant to polyenes like amphotericin $\mathrm{B}$ and nystatin than colonies grown in liquid culture. The ECM observed in Bcchs3a mutant could reduce permeability and penetration of drugs like camalexin into the fungal cell.

The increase in camalexin production could be due to the recognition by the host of a new pathogen-derived elicitor. The overexpression of the PAD3 gene is well observed at 18 hpi. However, in a standard test on onion epidermis, penetration of the Bcchs $3 a$ mycelium occurs only 24 hpi. Therefore, PAD3 gene induction most likely takes place before fungal entry in host tissue and could continue during early penetration stages, the mutant hyphae generating phytoalexin accumulation, necrosis, and pathogen restriction. Brummer and Steven (2009) have shown that components, covalently cross-linked in a network of the fungal cell wall, constituted ligands (pathogenassociated molecular patterns [PAMPs]) recognized by the host, inducing defense reactions. Cell wall and glucopeptide components of yeast or the CBEL (cellulose-binding elicitor lectin) from the cell wall of Phytophthora parasitica nicotianae have been reported to exhibit elicitor activity (Blechert et al. 1995; Gaulin et al. 2002, 2006; Hahn and Albersheim 1978; Suzuki et al. 2005). The CHS mutant Bcchs3a presents a change in its cell wall with $39 \%$ less chitin content (Soulié et al. 2006), which could lead to a modification of the ECM composition (Doss 1999). One possible hypothesis is that a molecule in the altered ECM could play an important role as an elicitor (PAMP) inducing the pad3 gene. The fact that germinated conidia of mutant $B c c h s 3 a$ without this ECM are virulent, reinforces this hypothesis. Preliminary studies on Bcchs $3 a$ and Bd90 ECM showed an interesting increase of galactose and mannose contents in the mutant. Mannose-rich glycans have been shown to induce plant defense. Indeed, Basse and associates (1992) have found an elicitor activity of a pure yeast glycoprotein in tomato cells; the elicitor activity resulting essentially from the glycan part composed of mannosyl residues. Glycoproteins, commonly secreted by fungi, often generate signals in the host plant. For the Bcchs $3 a$ mutant of $B$. cinerea, the increase in mannose levels in the ECM could therefore play an elicitor role in $A$. thaliana leaves, leading to accumulation of $P A D 3$ gene transcripts. In the case of human infection by pathogenic fungi, mannose-binding lectins (MBL) are cir- culating collectins and are recognized as important factors in nonspecific innate immune responses to pathogens (Brummer and Stevens 2009). These molecules bind glycopeptides containing mannose present at the surface of pathogenic micro-organisms and form complexes that activate the complement cascade and facilitate phagocytosis. MBL deficiency was associated with severe and repeated infections in infants and immunocompromised hosts, showing clearly an important role of MBL in host resistance. For Bcchs $3 a$ mutant, we thus suggest that mannose present in the ECM could play an important role as elicitor. This PAMP could be recognized by a carbohydratebinding protein receptor like MBL, inducing defense responses such as phytoalexin production. The presence of a new PAD3inducing elicitor in the altered ECM of the mutant Bcchs $3 a$ as a consequence of mycelium cell-wall alterations seems to be a plausible hypothesis. Now we need to investigate the presence of such a PAMP in the ECM of the mutant and determine its exact nature. An alternative hypothesis could be that this PAMP is already present in the Bd90 ECM but in a small quantity or masked by components due to BcCHS3a CHS activity.

Interestingly, in some cases (Fig. 1A), the mutant Bcchs3a escaped plant defenses and produced spreading lesions with the same lesion growth rate as wild-type strain Bd90. Preliminary results showed that camalexin accumulation at the edge of these spreading lesions corresponded to concentrations found for Bd90. This could indicate that mutant Bcchs $3 a$ does not provoke enhanced $P A D 3$ expression once deeply advanced into the plant tissues. Dynamic changes of cell-wall composition during plant infection have been shown for Magnaporthe grisea (Fujikawa et al. 2009) and a range of other plant pathogens (El Gueddarri et al. 2002). In Botrytis cinerea, similar cellwall changes could occur during infection, leading to the loss of the ECM in Bcchs3a mutant and the lack of overelicitation.

The accumulation of camalexin generated a decrease in virulence of the Bcchs $3 a$ mutant, but we found that it is not the sole cause of this defect. Bcchs $3 a$ mycelium adheres poorly to the plant surface, and this could explain why the infection process of mutant $B c c h s 3 a$ is always delayed ( $48 \mathrm{~h}$ ), even on pad3 leaves, compared with that of the wild-type strain. Little is known about genes involved in mycelium and hyphae adhesion to plant surfaces. Hydrophobins, unusual surface-active proteins secreted by fungi, are known to form an amphiphilic monolayer around hyphae, which mediates fungal attachment to hydrophobic surfaces (Wösten et al. 1994). However, we did not find any difference in the expression patterns of hydrophobin genes between the wild-type strain and the mutant $B c c h s 3 a$ (data not shown). Poor mycelium adhesion could be due to the presence of the above-mentioned ECM in the Bcchs $3 a$ mutant. Aspergillus fumigatus possesses a well-defined ECM (Latgé et al. 1994). In this fungus, galactofuranose (Galf) is a major molecule found particularly in cell-wall polysaccharides and ECM (Latgé 2009). A mutant lacking the afUGM1 gene encoding the UDP-galactopyranose mutase (last step in the Galf pathway) has been constructed by Lamarre and associates (2009). Interestingly, the major phenotype of the mutant was a modification of the cell-wall surface resulting in an increase in adhesion to different inert surfaces. In contrast, changing the cell-wall surface of $B$. cinerea CHS mutant Bcchs $3 a$ generated the loss of correct mycelium adhesion.

In this study, we established that CHS BcCHS3a of B. cinerea plays an important role at early stage of infection performed with mycelium inoculum. In nature, $B$. cinerea has a variety of modes of attack, conidia being a primary source of inoculum. Mycelium surviving within infected dead host tissues can also be a primary inoculum source, and infected wind-blown petals containing mycelium can be regarded as dispersal propagules 
in some cases (Williamson et al. 2007). Depending on the inoculum source, the infection process is not the same. Plants inoculated with mycelium showed hyphae growing on the plant surface heavily ramified into cell aggregates named 'infection cushions' before penetration (Choquer et al. 2007; Kunz et al. 2006). Plants inoculated with conidia showed frequent germtube penetration without previous ramification and appressorium-like structures (Fourie and Holz 1995; Tenberge 2004). We found that Bcchs $3 a$ gene is not or is little expressed in conidia inoculum (from $8 \mathrm{~h}$ postgermination). In addition, at this stage of development, we did not detect any ECM on germling conidia of Bcchs $3 a$ mutant. Virulence tests on A. thaliana ecotype Col-0 conducted with conidia suspension of $\mathrm{Bd} 90$ and $B c c h s 3 a$ revealed the same typical symptoms for the two strains. Thus, we conclude that CHS BcCHS3a is not involved at early conidia infection stages. These results show the importance of inoculum source during the infection process.

In conclusion, the use of both the fungal CHS mutant and the Arabidopsis pad3 mutant allowed us to evaluate the role of BcCHS3a during the infection process. The class III CHS is important for proper mycelium adhesion to the plant surface and rapid host-tissue penetration. Moreover, it plays a crucial role in protecting $B$. cinerea from early detection by the host defense system, either in masking PAMPs on the fungal cell surface or in avoiding mycelium cell-wall alterations leading to early recognition. Lack of the BcCHS3a enzyme allows the host plant to accumulate sufficiently high camalexin concentrations at the infection sites to arrest fungal growth before lesion formation.

\section{MATERIALS AND METHODS}

\section{Plant maintenance.}

Arabidopsis thaliana seed from ecotype Col-0 were obtained from the Institut National de la Recherche Agronomique (INRA) Versailles collection. The mutants AtrbohDF, Atfahl7tt5, pad2, and pad3 (pad3-1; Zhou et al. 1999) were provided by the Nottingham Arabidopsis Stock Center. All plants, A. thaliana, Phaseolus vulgaris (cv. Contender), and Vitis vinifera (cv. Chardonnay), were grown in nonsterile soil with a photoperiod of $16 \mathrm{~h}$ at $19^{\circ} \mathrm{C}\left(23^{\circ} \mathrm{C}\right.$ for $V$. vinifera $)$ and $70 \%$ of relative humidity.

\section{Culture of $B$. cinerea and infection method.}

The wild-type B. cinerea Bd90, collected in 1986 from grapevine in Bordeaux (Reignault et al. 1994), and a resulting mutant CHS of class III, Bcchs $3 a$ (Soulié et al. 2006), were grown on potato dextrose agar at $21^{\circ} \mathrm{C}$ with a 12 -h photoperiod. After 10 days, each strain produced a dense carpet of conidia. For spore infections, conidial suspensions $\left(10^{5}\right.$ conidia per milliliter $)$ were realized in Difco potato dextrose broth (PDB) diluted by half. Spore suspension (10- $\mu$ l droplets) were deposited on either A. thaliana leaves of 6-week-old plants, Phaseolus vulgaris cotyledon leaves of 10-day-old plants, or on young Vitis vinifera leaves. Camalexin determination and virulence tests were realized 4 dpi. RNA extractions were realized 18 and 48 hpi. For mycelium plug infections, each strain was grown on $1.5 \% \mathrm{ME}$ agar medium. One mycelium plug (3 $\mathrm{mm}$ in diameter), taken from the actively growing edge, was inverted onto the upper surface of one excised leaf. Infected leaves were kept in a petri dish under high humidity and were incubated with a photoperiod of $12 \mathrm{~h}$ at $21^{\circ} \mathrm{C}$. For each strain, 30 leaves were inoculated, and mean lesion surfaces were determined daily, using OptiLab/Pro-F 2.6.3. Growth rates were determined $\left(\mathrm{cm}^{2} \mathrm{~h}^{-1}\right)$ and were analyzed using the Kruskal-Wallis test. Camalexin was determined 3 dpi and RNA extractions realized after 18 and 48 hpi.

\section{Microscopy.}

For the assay of onion epidermis penetration, we adapted the procedure of Chida and Sisler (1987). Mycelium plugs (6 mm in diameter) were applied on the hydrophobic side of onion epidermis and were kept in a humid chamber for 10,15 , and $24 \mathrm{~h}$ at $21^{\circ} \mathrm{C}$. After staining with cotton blue, samples were examined under a light microscope.

For visualization of the ECM of germling conidia, suspensions were realized in PDB diluted by half. Suspensions $(1 \mathrm{ml})$ were spread on a cellophane sheet in Petri dishes and were incubated $7 \mathrm{~h}$ at $21^{\circ} \mathrm{C}$. Samples were stained with Calcofluor white $(0.01 \%)$ for $30 \mathrm{~min}$, were rinsed in $\mathrm{H}_{2} \mathrm{O}$, and were mounted in a medium for fluorescence observation (Vectashield; Vector Laboratories, Burlingame, CA, U.S.A.) on microscope slides. Observations were performed under UV light with a Zeiss Axiophot microscope (Oberkochen, Germany).

\section{RNA extraction and real-time PCR.}

In planta. For mycelium infection, total RNA was extracted from $30 \mathrm{mg}$ of fresh weight corresponding to five foliar disks of $A$. thaliana Col-0 ( $8 \mathrm{~mm}$ in diameter), cut out under the mycelium plug. For spore infection, six spore droplets were applied on the leaves, which were washed after incubation, and total RNA was extracted from $100 \mathrm{mg}$ of fresh weight. Infected tissues were ground in liquid nitrogen and were extracted using Trizol reagent (Invitrogen, Carlsbad, CA, U.S.A.). RT was performed using an oligo-dT20 for a primer and Superscript II RnaseH-reverse transcriptase (Invitrogen). Real-time quantitative PCR analysis was performed using a 7300 system (Applied Biosystems, Foster City, CA, U.S.A.). A 1:5 dilution of cDNA $(5 \mu \mathrm{l})$ was amplified in a 15$\mu \mathrm{l}$ reaction mix containing Power SYBR green PCR master mix (Applied Biosystems) and $0.5 \mu \mathrm{M}$ of each primer. The primers used were fwpad3 (5'-CCATCATCGGAAACTTAC ACCAA-3'), revpad3 (5'-GGCGAGATTACGGCGATTC-3'), fwact $\left(5^{\prime}\right.$-CGCCATTGCTCGTGTTGAC-3'), revact $\left(5^{\prime}-\mathrm{TCG}\right.$ GCAGTGGTGGAGAAAGT-3'), fwEF1 (5'-CGTCACCCTA GCCGCTTTAC-3') and revEF1 (5'-CCCATGGTTAGAGAC TGTCAAACA-3'). Gene expression values were normalized to expression of the $A$. thaliana gene EF1 or B. cinerea gene actin. For $P A D 3$ expression, serial dilutions of $100 \mathrm{ng}$ to 0.032 ng of pure cDNA of $B$. cinerea were amplified with the act1/ act2 primer couple, which is specific to $B$. cinerea actin. Cycle thresholds obtained were used to trace a calibration curve, which allowed quantification of fungal cDNA in infected tissues (Gachon and Saindrenan 2004).

In vitro. A dense $\left(10^{9}\right.$ conidia $\left.\mathrm{ml}^{-1}\right)$ conidial suspension $(5 \mathrm{ml}$ each) was spread on a cellophane sheets in petri dishes and, after incubation for $5,10,18$, and $72 \mathrm{~h}$, total RNA was extracted with the same method described above. The primers used were fwBcchs3a (5'-GAAACGTATGCGAACGAT-3'), revBcchs3a (5'-AGGAGTGTCGGTTTGTG-3') and fwact/revact cited above. Gene expression values were normalized to the expression of the $B$. cinerea gene actin.

\section{In vitro effect of camalexin on the growth of $B$. cinerea.}

In order to measure fungal growth, we applied a bioassay according to Ludwig and Boller (1990). Antifungal activity of camalexin was estimated following turbidity of fungal cultures growing in microtiter plate wells. Fungal spores were germinated in liquid Czapek culture medium (containing per liter: $2.5 \mathrm{~g} \mathrm{NaNO}_{3}, 0.5 \mathrm{~g} \mathrm{KCl}, 0.5 \mathrm{~g} \mathrm{MgSO}_{4} \cdot 7 \mathrm{H}_{2} 0,10 \mathrm{mg}$ $\mathrm{FeSO}_{4} \cdot 7 \mathrm{H}_{2} \mathrm{O}, 1 \mathrm{~g} \mathrm{~K}_{2} \mathrm{HPO}_{4}$, and $10 \mathrm{mg} \mathrm{Na}$ molybdate; the medium was supplemented with $1.5 \%$ glucose) for $3 \mathrm{~h}$. Germlings $\left(5 \times 10^{3}\right.$ spores $\mathrm{ml}^{-1}$ final concentration) were then applied in wells of a microtiter plate (Techno Plastic Products, Trasadingen, Switzerland) in the presence of different cama- 
lexin concentrations: $0,5,10,25$, or $50 \mu \mathrm{g} \mathrm{ml} l^{-1}$ (total incubation volume of $90 \mu \mathrm{l}$ ). Growth was determined by measuring absorbance at $405 \mathrm{~nm}$ every $12 \mathrm{~h}$. Results of two independent tests, each including 12 replicates per condition, were analyzed in detail for the values obtained at 4 dpi. A multivariate linear regression, in which the continuous dependent variable was the absorbance, was used, and it included camalexin concentrations, strain, and interaction terms between concentrations and strain. The statistical tests were two-tailed, and the value of $\alpha$ was set to $5 \%$.

\section{Camalexin extraction and determination.}

For each extraction, six leaf disks (total surface, $120 \mathrm{~mm}^{2}$ ) were combined. For wild-type strain Bd90, leaf disks were sampled in the region immediately surrounding the lesion $(+2 \mathrm{~mm})$ and only healthy tissue was harvested for extraction (total surface, $33 \mathrm{~mm}^{2}$ ). For mutant Bcchs $3 a$, whole disks immediately under the mycelium plug were used (Fig. 4). Mock inoculation consisted of malt-agar plugs without mycelium, and the leaf disks under the malt-agar plug were used for extraction. Camalexin extractions were performed 3 dpi. Means of 20 extractions for $\mathrm{Bd} 90$ and six extractions for Bcchs $3 a$ and mock inoculation were calculated and analyzed using the Mann-Whitney test. Extraction and purification was conducted as described by Glazebrook and Ausubel (1994) using methanol and chloroform extraction and silica thin-layer chromatography. Camalexin was visualized by its blue fluorescence under an ultraviolet lamp $(365 \mathrm{~nm})$. The silica containing camalexin was scraped off the plate and extracted into $1 \mathrm{ml}$ of methanol. The emission at $385 \mathrm{~nm}$ after excitation at $315 \mathrm{~nm}$ was measured with a Hitachi F2000 fluorometer (Hitachi Ltd, Tokyo), and the camalexin concentration was calculated by comparison with a standard curve obtained by using purified camalexin provided by J. Glazebrook (University of Minnesota, Saint Paul, MN, U.S.A.).

In order to follow camalexin degradation during in vitro growth of $B$. cinerea in the microtiter plate bioassay, $30 \mu \mathrm{l}$ of filtrate were separated on silica thin-layer chromatography plates. Camalexin was then visualized as described above.

\section{Extraction and composition of the ECM.}

Mycelium grown on cellophane sheets for 4 days was scraped off and was shaken in $150 \mathrm{mM} \mathrm{NaCl}$. After 5 min of centrifugation at $4,000 \times g$, the supernatant was poured in dialysis bags (molecular weight cut off $=3,500$ ) (Spectrum Medical Industries, Carl Roth $\mathrm{GmbH}$, Karlsruhe, Germany) and was dialyzed against water for $24 \mathrm{~h}$. Samples were then lyophilized.

Total neutral hexoses of ECM were analyzed and quantified by the phenol-sulfuric acid procedure, using glucose as standard (Dubois et al. 1956). Hexoses were identified by gas liquid chromatography as their alditol acetates obtained after hydrolysis (4 $\mathrm{N}$ trifluoroacetic acid, $100^{\circ} \mathrm{C}$ for $4 \mathrm{~h}$ ), according to Sawardeker and associates (1967). GLC was performed on a Perichrom 2100 instrument with a flame ionization detector using a BP-1 capillary column $(30 \mathrm{~m} \times 0.32 \mathrm{~mm}$ id) (Scientific Instrument Services, Inc., Ringoes, NJ, U.S.A.), under the following conditions: gas vector and pressure, helium 0.7 bar; temperature program, 120 to $180^{\circ} \mathrm{C}$ at $2^{\circ} \mathrm{C}$ per min and 180 to $240^{\circ} \mathrm{C}$ at $4^{\circ} \mathrm{C}$ per min.

\section{ACKNOWLEDGMENTS}

We are indebted to M. Fagard (INRA, Paris) for providing Arabidopsis genotypes and J. Glazebrook for camalexin (Department of Plant Biology, University of Minnesota). We thank N. K. Peters for revising the English of the manuscript.

\section{LITERATURE CITED}

Aufauvre-Brown, A., Mellado, E., Gow, N. A. R., and Holden, D. W. 1997. Aspergillus fumigatus chsE: A gene related to CHS3 of Saccharomyces cerevisiae and important for hyphal growth and conidiophore development but not pathogenicity. Fungal Genet. Biol. 21:141-152.

Basse, C. W., Bock, K., and Boller, T. 1992. Elicitors and suppressors of the defense response in tomato cells. J. Biol. Chem. 267:10258-10265.

Beauvais, A., Schmidt, C., Guadagnini, S., Roux, P., Perret, E., Henry, C., Paris, S., Mallet, A., Prévost, M.-C., and Latgé, J.-P. 2007. An extracellular matrix glues together the aerial-grown hyphae of Aspergillus fumigatus. Cell. Microbiol. 9:1588-1600.

Beth-Din, A., and Yarden, O. 2000. The Neurospora crassa chs3 gene encodes an essential class I chitin synthase. Mycologia 92:65-73.

Blechert, S., Brodschelm, W., Hoelder, S., Kammerer, L., Kutchan, T., Mueller, M. J., Xia, Z. Q., and Zenk, M. H. 1995. The octadecanoid pathway: Signal molecules for the regulation of secondary pathways. Proc. Natl. Acad. Sci. U.S.A. 92:4099-4105.

Borgia, P. T., Iartchouk, N., Riggle, P. J., Winter, K. R., Koltin, Y., and Bulawa, C. E. 1996. The chsB gene of Aspergillus nidulans is necessary for normal growth and development. Fungal Genet. Biol. 20:193-203. Fungal Genet. Biol. Erratum. 1996. 20:314.

Bowen, A. R., Chen-Wu, J. L., Momany, M., Young, R., Szanislo, J. P., and Robbins, P. W. 1992. Classification of fungal chitin synthases. Proc. Natl. Acad. Sci. U.S.A. 89:519-523.

Bowman, S. M., and Free, S. J. 2006. The structure and synthesis of the fungal cell wall. Bioessays. 28:799-808.

Brummer. E., and Stevens, D. A. 2009. Collectins and fungal pathogens: Roles of surfactant proteins and mannose binding lectin in host resistance. Med. Mycol. 1-13.

Chassot, C., Buchala, A., Schoonbeek, H-J., Métraux, J-P., and Lamotte, O. 2008. Wounding of Arabidopsis leaves causes a powerful but transient protection against Botrytis infection. Plant J. 55:555-567.

Chida, T., and Sisler, H. D. 1987. Restoration of appressorial penetration ability by melanin precursors in Pyricularia oryzae treated with antipenetrants and in melanin-deficient mutants. J. Pestic. Sci. 12:49-55.

Cantu, D., Greve, L.C., Labavitch, J.M., and Powell, A. L. T. 2009. Characterization of the cell wall of the ubiquitous plant pathogen Botrytis cinerea. Mycol. Res. 113:1396-1403.

Choquer, M., Boccara, M., Gonçalves, I. R., Soulié, M.-C., and VidalCros, A. 2004. Survey of the Botrytis cinerea chitin synthase multigenic family through the analysis of six euascomycetes genomes. Eur. J. Biochem. 271:2153-2164.

Choquer, M., Fournier, E., Kunz, C., Levis, C., Pradier, J-M., Simon, A., and Viaud M. 2007. Botrytis cinerea virulence factors: New insights into a necrotrophic and polyphageous pathogen. FEMS (Fed. Eur. Microbiol. Soc.) Microbiol. Lett. 277:1-10.

Culp, D. W., Dodge, C. L., Miao, Y., Li, L., Sag-Ozkal, D., and Borgia, P. T. 2000. The chs A gene from Aspergillus nidulans is necessary for maximal conidiation. FEMS (Fed. Eur. Microbiol. Soc.) Microbiol. Lett. 182:349-353.

Denby, K. J., Kumar, P., and Kliebenstein, D. J. 2004. Identification of Botrytis cinerea susceptibility loci in Arabidopsis thaliana. Plant J. 38:473-486.

Diaz, J., ten Have, A., and van Kan, J. A. L. 2002. The role of ethylene and wound signaling in resistance of tomato to Botrytis cinerea. Plant Physiol. 129:1341-1351.

Din, A. B., and Yarden, O. 1994. The Neurospora crassa chs-2 gene encodes a non-essential chitin synthase. Microbiol. 140:2189-2197.

Din, A. B., Specht, C. A., Robbins, P. W., and Yarden, O. 1996. Chs-4, a class IV chitin synthase gene from Neurospora crassa. Mol. Gen. Genet. 250. 214-222.

Doss, R. P. 1999. Composition and enzymatic activity of the extracellular matrix secreted by germlings of Botrytis cinerea. Appl. Environ. Microbiol. 65:404-408.

Doss, R. P., Potter, S. W., Soeldner, A. H., Christian, J. K., and Fukunaga, L. E. 1995. Adhesion of germlings of Botrytis cinerea. Appl. Environ. Microbiol. 61:260-265.

Dubois, M., Gilles, K. A., Hamilton, J. K., Rebers, P. A., and Smith, F. 1956. Colorimetric method for determination of sugars and related substances. Anal. Chem. 28:350-356.

El Gueddari, N., Rauchhaus, U., Moerschbacher, B. M., and Deising, H. B. 2002. Developmentally regulated conversion of surface-exposed chitin to chitosan in cell walls of plant pathogenic fungi. New Phytol. 156:103-112.

Ferrari, S., Plotnikova, J. M., De Lorenzo, G., and Ausubel, F. M. 2003. Arabidopsis local resistance to Botrytis cinerea involves salicylic acid and camalexin and requires EDS4 and PAD2, but not SID2, EDS5 or PAD4. Plant J. 35:193-205.

Ferrari, S., Galletti, R., Denoux, C., De Lorenzo, G., Ausubel, F. M., and 
Dewdney, J. 2007. Resistance to Botrytis cinerea induced in Arabidopsis by elicitors is independent of salicylic acid, ethylene, or jasmonate signaling but requires PHYOALEXIN DEFICIENTS. Plant Physiol. 144:367-379.

Fourie, J. F., and Holz, G. 1995. Initial infection processes by Botrytis cinerea on nectarine and plum fruit and the development of decay. Phytopathology 85:82-87.

Fujikawa, T., Kuga, Y., Yano, S., Yoshimi, A., Tachiki, T., Abe, K., and Nishimura, M. 2009. Dynamics of cell wall components of Magnaporthe grisea during infectious structure development. Mol. Microbiol. 73:553-570.

Gachon, C., and Saindrenan, P. 2004. Real-time PCR monitoring of fungal development in Arabidopsis thaliana infected by Alternarian brassicola and Botrytis cinerea. Plant Physiol. Biochem. 42:367-371.

Garcera-Teruel, A., Xoconostle-Cazares, B., Rosas-Quijano, R., Ortiz, L., Leon-Ramirez, C., Specht, C. A., Sentandreu, R., and Ruiz-Herrera, J. 2004. Loss of virulence in Ustilago maydis by Umchs6 gene disruption. Res. Microbiol. 155:87-97.

Gaulin, E., Jauneau, A., Villalba, F., Rickauer, M., Esquerré-Tugayé, M-T., and Bottin, A. 2002. The CBEL glycoprotein of Phytophthora parasitica var. nicotianae is involved in cell wall deposition and adhesion to cellulosic substrates. J. Cell Sci. 115:4565-4575.

Gaulin, E., Dramé, N., Lafitte, C., Torto-Alalibo, T., Martinez, Y., Ameline-Torregrosa, C., Khatib, M., Mazarguil, H., Villalba-Mateos, F., Kamoun, S., Mazars, C., Dumas, B., Bottin, A., Esquerré-Tugayé, M-T., and Rickauer, M. 2006. Cellulose binding domains of a Phytophthora cell wall protein are novel pathogen-associated molecular patterns. Plant Cell 18:1766-1777.

Glazebrook, J. 2005. Contrasting mechanisms of defense against biotrophic and necrotrophic pathogens. Annu. Rev. Phytopathol. 43:205-227.

Glazebrook, J., and Ausubel, F. M. 1994. Isolation of phytoalexin-deficient mutants of Arabidopsis thaliana and characterization of their interactions with bacterial pathogens. Proc. Natl. Acad. Sci. U.S.A. 91:89558959

Gold, S., and Kronstad, J. 1994. Disruption of two genes for chitin synthase in the phytopathogenic fungus Ustilago maydis. Mol. Microbiol. 11:897-902.

Gourgues, M., Brunet-Simon, A., Lebrun, M. H., and Levis, C. 2004. The tetraspanin BcPIs1 is required for appressorium-mediated penetration of Botrytis cinerea into host plant leaves. Mol. Microbiol. 51:619-629.

Hammond-Kosack, K. E., and Jones, J. D. 1996. Resistance gene-dependent plant defence responses. Plant Cell 8:1773-1791.

Hahn, M. G., and Albersheim, P. 1978. Host-pathogen interactions. Plant Physiol. 62:107-111.

Horiuchi, H., Fujiwara, M., Yamashita, S., Ohta, A., and Takagi, M. 1999. Proliferation of intrahyphal hyphae caused by disruption of $\operatorname{csmA}$, which encodes a class $\mathrm{V}$ chitin synthase with a myosin motor-like domain in Aspergillus nidulans. J. Bacteriol. 181:3721-3729.

Kliebenstein, D. J., Rowe, H. C., and Denby, K. J. 2005. Secondary metabolites influence Arabidopsis/Botrytis interactions: Variation in host production and pathogen sensitivity. Plant J. 44:25-36.

Kunz, C., Vandelle, E., Rolland, S., Poinssot, B., Bruel, C., Cimerman, A., Zotti, C., Moreau, E., Vedel, R., Pugin, A., and Boccara, M. 2006. Characterization of a new, non-pathogenic mutant of Botrytis cinerea with impaired plant colonization capacity. New Phytol. 170:537-550.

Lamarre, C., Beau, R., Balloy, V., Fontaine, T., Wong Sak Hoi, J., Guadagnini, S., Berkova, N., Chignard, M., Beauvais, A., and Latgé, J. P. 2009. Galactofuranose attenuates cellular adhesion of Aspergillus fumigatus. Cell Microbiol. 11:1612-1623.

Latgé, J.-P. 2007. The cell wall: A carbohydrate armour for the fungal cell. Mol. Microbiol. 66:279-290.

Latgé, J.-P. 2009. Galactofuranose containing molecules in Aspergillus fumigatus. Med. Mycol. 47:S104-S109.

Latgé, J.-P., Kobayashi, H., Debeaupuis, J. P., Diaquin, M., Sarfati, J., Wieruszeski, J. M., Parra, E., Bouchara, J. P., and Fournet, B. 1994 Chemical and immunological characterization of the extracellular galactomannan of Aspergillus fumigatus. Infect. Immun. 62:54245433.

Leroux, P., Fritz, R., Debieu, D., Albertini, C., Lanen, C., Bach, J., Gredt, M., Chapeland, F. 2002. Mechanisms of resistance to fungicides in filed strains of Botrytis cinerea. Pest Manag. Sci. 58:876-888.

Liu, H., Kauffman, S., Becker, J. M., and Szaniszlo, P. J. 2004. Wangiella (Exophiala) dermatitidis WdChs5p, a class V chitin synthase, is essential for sustained cell growth at temperature of infection. Eukaryot. Cell. 3:40-51.

Ludwig, A., and Boller, T. 1990. A method for the study of fungal growth inhibition by plant proteins. FEMS (Fed. Eur. Microbiol. Soc.) Microbiol. Lett. 69:61-66.

Madrid, M. P., Di Pietro, A., and Roncero, M. I. 2003. Class V chitin synthase determines pathogenesis in the vascular wilt fungus Fusarium oxysporum and mediates resistance to plant defence compounds. Mol. Microbiol. 47:257-266.

Martin-Udiroz, M., Madrid, M. P., and Roncero, M. I. 2004. Role of chitin synthase genes in Fusarium oxysporum. Microbiology. 150:3175-3187.

Martin-Urdiroz, M., Roncero, M. I., Gonzales-Reyes, J. A., and RuizRoldan, C. 2008. ChsVb, a class VII chitin synthase involved in septation, is critical for pathogenicity in Fusarium oxysporum. Eukaryot. Cell. 7:112-121.

Mayer, A. M., Staples, R. C., and Gil-ad, N. L. 2001. Mechanisms of survival of necrotrophic fungal plant pathogens in hosts expressing the hypersensitive response. Phytochem. 58:33-41.

Mellado, E., Aufavre-Brown, A., Gow, N. A. R., and Holden, D. W. 1996. The Aspergillus fumigatus chsC and chsG genes encode class III chitin synthases with different functions. Mol. Microbiol. 20:667-679.

Mellado, E., Dubreucq, G., Mol, P., Sarfati, J., Paris, S., Diaquin, M. Holden, D. W., Rodriguez-Tudela, J. L., and Latgé, J. P. 2003. Cell wall biogenesis in a double chitin synthase mutant (chsG-/chsE-) of Aspergillus fumigatus. Fungal Genet. Biol. 38:98-109.

Motoyama, T., Kojima, N., Horiuchi, H., Ohta, A., and Takagi, M. 1994. Isolation of a chitin synthase gene (chsC) of Aspergillus nidulans. Biosci. Biotechnol. Biochem. 58:2254-2257.

Munro, C. A., Winter, K., Buchan, A., Henry, K., Becker, J. M., Brown, A. J., Bulawa, C. E., and Gow, N. A. 2001. Chs1 of Candida albicans is an essential chitin synthase required of synthesis of the septum and for cell integrity. Mol. Microbiol. 39:1414-1426.

Pedras, M. S. C., and Ahiahonu, P. W. K. 2002. Probing the phytopathogenic stem rot fungus with phytoalexins and analogues: Unprecedented glucosylation of camalexin and 6-methoxycamalexin. Bioorg. Med. Chem. 10:3307-3312.

Pedras, M. S. C., and Ahiahonu, P. W. K. 2004. Metabolism and detoxification of phytoalexins and analogs by phytopathogenic fungi. Phytochemistry 66:391-411.

Pedras, M. S. C., and Kahn, A. Q. 1997. Unprecedented detoxification of the cruciferous phytoalexin camalexin by a root phytopathogen. Bioorg. Med. Chem. Lett. 7:2255-2260.

Pedras, M. S.C., and Kahn, A. Q. 2000. Biotransformation of the phytoalexin camalexin by the phytopathogen Rhizoctonia solani. Phytochemistry. 53:59-69.

Reignault, P., Mercier, M., Bompeix, G., and Boccara, M. 1994. Pectin methyl esterase from Botrytis cinerea: Physiological, biochemical and immunochemical studies. Microbiol. 140:3249-3255.

Roncero, C. 2002. The genetic complexity of chitin synthesis in fungi. Curr. Genet. 41:367-378.

Ruiz-Herrera, J., Gonzalez-Prieto, J. M., and Ruiz-Medrano, R. 2001 Evolution and phylogenetic relationships of chitn synthases from yeasts and fungi. FEMS (Fed. Eur. Microbiol. Soc.) Yeast Res. 1438:1-10.

Sanz, M., Carrano, L., Jiménez, C., Candiani, G., Trilla, J. A., Duran, A., and Roncero, C. 2005. Candida albicans strains deficient in CHS7, key regulator of chitin synthase III, exhibit morphogenetic alterations and attenuated virulence. Microbiology 151:2623-2636.

Sawardeker, J. S., Sloneker, J. H., and Jeanes A. 1967. Quantitative determination of monosaccharides as their alditol acetates by gas liquid chromatography. Anal. Chem. 37:350-356

Schouten, A., Tenberge, K. B., Vermeer, J., Stewart, J., Wagemakers, L., Williamson, B., and van Kan, J. A. L. 2002. Functional analysis of an extracellular catalase of Botrytis cinerea. Mol. Plant Pathol. 3:227-238.

Schuhegger, R., Nafisi, M., Mansourova, M., Petersen, B. L., Olsen, C. E., Svatos, A., Halkier, B. A., and Glawischnig, E. 2006. CYP71B15 (PAD3) catalyzes the final step in camalexin biosynthesis. Plant Physiol. 141:1248-1254.

Soulié, M.-C., Périno, C., Piffeteau, A., Choquer, M., Malffati, P., Cimerman, A., Kunz, C., Boccara, M., and Vidal-Cros, A. 2006. Botrytis cinerea virulence is drastically reduced after disruption of chitin synthase class III gene (Bcchs3a). Cell. Microbiol. 8:1310-1321.

Soulié, M.-C., Piffeteau, A., Choquer, M., Boccara, M., and Vidal-Cros A. 2003. Disruption of Botrytis cinerea class I chitin synthase abolished in vitro activity and reduced pathogenicity on vine leaf. Fungal Genet. Biol. 43:38-46.

Specht, C. A., Liu, Y., Robbins, P. W., Bulawa, C. E., Iartchouk, N., Winter, K. R., Riggle, P. J., Rhodes, J. C., Dodge, C. L., Culp, D. W., and Borgia, P. T. 1996. The chsD and chsE genes of Aspergillus nidulans and their roles in chitin synthesis. Fungal Genet. Biol. 20:153-167.

Stefanato, F. L., Abou-Mansour, E., Buchala, A., Kretschmer, M., Mosbach, A., Hahn, M., Bochet, C. G., Métraux, J.-P., and Schoonbeek, H.-J. 2009. The ABC transporter BcatrB from Botrytis cinerea exports camalexin and is a virulence factor on Arabidopsis thaliana. Plant $\mathrm{J}$. 58:499-510.

Suzuki, H., Reddy, M. S. S., Naoumkina, M., Aziz, N., May, G. C., Huhman, D. V., Summer, L. W., Blount, J. W., Mendes, P., and Dixon, R. A. 2005. Methyl jasmonate and yeast elicitor induce differential tran- 
scriptional and metabolic re-programming in cell suspension cultures of the model legume Medicago truncatula. Planta. 220:696-707.

Tenberge, K. B. 2004. Morphology and cellular organisation in Botrytis interactions with plants. Pages 67-84 in: Botrytis: Biology, Pathology and Control. Y. Elad, B. Williamson, P. Tudzynski, and N. Delen, eds. Kluwer Academics Publishers, Dordrecht. The Netherlands.

Thomma, B. P., Eggermont, K., Tierens, K. F., Broekaert, W. F. 1999. Requirement of functional ethylene-insensitive 2 gene for efficient resistance of Arabidopsis to infection by Botrytis cinerea. Plant Physiol. 121:1093-1102.

Van Baarlen, P., Woltering, E. J., Staats, M., and van Kan, J. A. L. 2007. Histochemical and genetic analysis of host and non-host interactions of Arabidopsis with three Botrytis species: An important role for cell death control. Mol. Plant Pathol. 8:41-54.

Wang, Z., Zheng, L., Hauser, M., Becker, J. M., and Szaniszlo, P. J. 1999. WdChs $4 \mathrm{p}$, a homolog of chtin synthase 3 in Saccharomyces cerevisiae, alone cannot support the growth of Wangiella (Exophiala) dermatitidis at temperature of infection. Infect. Immun. 67:6619-6630.

Wang, Z., Zheng, L., Liu, H., Wang, Q., Hauser, M., Kaufman, S., Becker, J. M., and Szaniszlo, P. J. 2001. WdChs2, a class I chitin synthase, together with WdChs3p (class III) contributes to virulence in Wangiella (Exophiala) dermatitidis. Infect. Immun. 69:7517-7526.

Werner, S., Sugui, J. A., Steinberg, G., and Deising, H. B. 2007. A chitin synthase with a myosin-like motor domain is essential for hyphal growth, appressorium differentiation and pathogenicity of the maize anthracnose fungus Colletotrichum graminicola. Mol. Plant-Microbe Interact. 20:1555-1567.

Williamson, B., Tudzynski, B., Tudzynski, P., and van Kan, J. A. L. 2007. Botrytis cinerea: The cause of grey mould disease. Mol. Plant Pathol. 8:561-580.

Wösten, H. A., Asgeirsdóttir, S. A., Krook, J. H., Drenth, J. H., and Wessels, J. G. 1994. The fungal hydrophobin Sc3p self-assembles at the surface of aerial hyphae as a protein membrane constituting the hydrophobic rodlet layer. Eur J Cell Biol. 63:122-129

Xoconostle-Cazares, B., Leon-Ramirez, C., and Ruiz-Herrera, J. 1996. Two chitin synthase genes from Ustilago maydis. Microbiology. 142:377-387.

Xoconostle-Cazares, B., Specht, C. A., Robbins, P. W., Liu, Y., Leon, C., and Ruiz-Herrera, J. 1997. Umchs5, a gene coding for a class IV chitin synthase in Ustilago maydis. Fungal Genet. Biol. 22:199-208.

Yarden, O., and Yanofsky, C. 1991. Chitin synthase 1 plays a major role in cell wall biogenesis in Neurospora crassa. Genes Dev. 5:2420-2430.

Zheng, L., Mendoza, L., Zheng, W., Liu, H., Park, C., Kauffman, S. Becker, J. M., and Szaniszlo, P. J. 2006. WdChs1p, a class II chitin synthase, is more responsible than WdChs2p, (Class I) for normal yeast reproductive growth in the polymorphic, pathogenic fungus Wangiella (Exophiala) dermatitidis. Arch. Microbiol. 18:316-329.

Zhou, N., Tootle, T. L., and Glazebrook, J. 1999. Arabidopsis PAD3, a gene required for camalexin biosynthesis, encodes a putative cytochrome P450 monoxygenase. Plant Cell. 11:2419-2428. 